\title{
Time-phasing and decoupling points as analytical tools for purchasing
}

\author{
J. Bäckstrand ${ }^{1}$, J. Wikner ${ }^{1,2}$ \\ ${ }^{1}$ Department of Industrial Engineering and Management, Jönköping University, Jönköping, Sweden \\ ${ }^{2}$ Department of Management and Engineering, Linköping University, Linköping, Sweden
}

(jenny.backstrand@jth.hj.se)

\begin{abstract}
Customization and customer-driven manufacturing are both explicitly based on end-customer relations and customer requirements. The impact of these aspects on internal operations is relatively well known and can be investigated using time phasing and decoupling points. These tools are however rarely used for analyzing purchased material. Based on the time phased product structure, items are categorized according to three criteria: driver, uniqueness, and make/buy. Purchased items can thus be identified using the last criteria and then driver and uniqueness are used as a point of departure for categorizing purchased material. The approach hence provides a platform for development of supplier relations based on the customer requirements which is the core theme of the method for customer-driven purchasing.
\end{abstract}

Keywords - Decoupling points, purchasing, time-phased product structure

\section{INTRODUCTION}

Purchasing as a profession has developed from being focused on negotiation for lowest price to a role with responsibility for supporting the company's order winners. Kraljic [1] pioneered this development when he outlined a more sophisticated approach to supplier interaction. Kraljic differentiated the interaction with suppliers based on profit impact and supply risk resulting in the well-known Kraljic's matrix. Profit impact is however a very general concept and to further operationalize the approach profit impact may be substituted by order winners [2]. By introducing the company's order winners as a key factor for supplier interaction it is obvious that purchasing is not only about lowest price, it is rather about identifying the best possible support for the company's competitive priorities. The tools available for aligning purchasing with the competitive priorities of the company are however quite limited even if this field has received more attention recently.

One obvious link between the supplier side and the customer side of the company is the customer order received. In some cases purchasing may be performed quite independently from the customer order but in others the activities of the supplier may be directly related to the customer of the company [2]. This scenario can be analyzed based on the lead times of the constituent items in the product. The objective of this research is to extend the use of time-phased product structures to aid in purchasing decisions. In this paper a lead time based analysis model for different purchasing situations is thus presented. By visualizing the supply lead time in a timephased product structure and relating it to delivery lead time, different scenarios for purchasing are identified. The lead time analysis outlined here constitutes the first phase of the customer-driven purchasing method (the CDP method) as described in [3].

The CDP-method consists of three phases but the approach outlined here is mainly related to the first phase. The objective of the first phase of the CDP-method is to identify and analyze basic item information and more specifically to distinguish if an item is forecast-driven or customer-order-driven, if it is purchased or manufactured and to determine its level of customization. Next the methodology employed is outlined and then the first five steps of the CDP-method are described. Thereafter follows a detailed example of how to perform a timephased analysis of a product.

\section{METHODOLOGY}

The lead time analysis is a conceptual framework and the results are based on analytical conceptual research. The sequence of the lead time analysis is developed based on Wacker's definition of theory building where analytical conceptual frameworks are tested with empirical case studies [4]. The CDP-method is conceptually developed by the authors of [3] and tested within the KOPeration research project involving six companies in Sweden within different industries. The companies involved were Combitech $\mathrm{AB}$ in Linköping, Ericsson $\mathrm{AB}$ in Borås, Fagerhult $\mathrm{AB}$ in Habo, Husqvarna $\mathrm{AB}$ in Huskvarna, Parker Hannifin $\mathrm{AB}$ in Trollhättan, and Siemens Turbomachinery $\mathrm{AB}$ in Finspång. During the research project, the CDP-method was applied to more than 20 products at the case companies.

\section{THE CDP-METHOD}

The CDP-method, as defined by [3], constitutes of three phases covering 12 steps. As outlined above the focus below is on the first phase and therefore the five initial steps, corresponding to phase one, are summarized here:

- Step 1: Identify product (family) and bill-of-materials (BoM). The point of departure of the method is to select a product or a product family to be investigated in addition to identify the complete product structure. 
The key information at this stage is the items the product is made up of.

- $\quad$ Step 2: Identify supply lead time for each item. Each identified item from step 1 is here complemented with the manufacturing lead time or the purchasing lead time, depending on whether it is a make or buy item. The cumulative lead time, i.e. the supply lead time, can then be calculated for each item.

- Step 3: Differentiate forecast-driven items from customer-order-driven items. Each item can be categorized in terms of level of certainty, as either being forecast-driven or customer-order-driven. The categorization is based on the delivery lead time in relation to the supply lead time.

- $\quad$ Step 4: Differentiate generic items from unique items. It is also important to differentiate between different levels of customization. In this context this is referred to as properties on a scale from generic to customer order unique in line with [5].

- $\quad$ Step 5: Differentiate make from buy items. The initial four steps are generic in terms of make or buy items and can hence be used for different purposes related to for example selecting postponement strategies and planning strategies. This fifth step is however targeting the differentiation of buy items as a gateway to next phase in the CDP-method that focuses on purchased items.

Steps 6-12 are not further discussed here.

\section{ANALYSIS BASED ON THE TIME PHASED PRODUCT STRUCTURE}

The first step of the CDP-method involves the selection of a product and its BoM. In this case a fictitious end product $\mathrm{Z}$ is used as an example, see Fig. 1. The example is based on [6] but the letters representing the products have been changed.

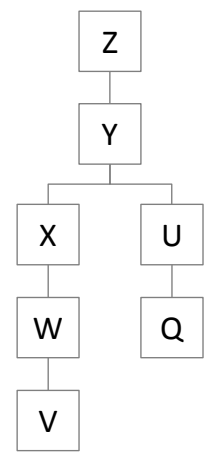

Fig. 1. Product structure for end product $\mathrm{Z}$

According to the second step of the CDP method, the supply lead time for each item $\left(\mathrm{S}_{\mathrm{i}}\right)$ should be defined. The supply lead time (S) is the total time it takes to replenish a product corresponding to the cumulative lead time of the product. The point of departure for this analysis is the time phased product structure as shown in Fig. 2. Time phasing refers to illustrating the BoM where each item is represented by an arrow or a line where the length of the arrow corresponds to the lead time of that item. This is a technique with a long history, see e.g. [7] and is somewhat similar to some instances of Gantt charts.

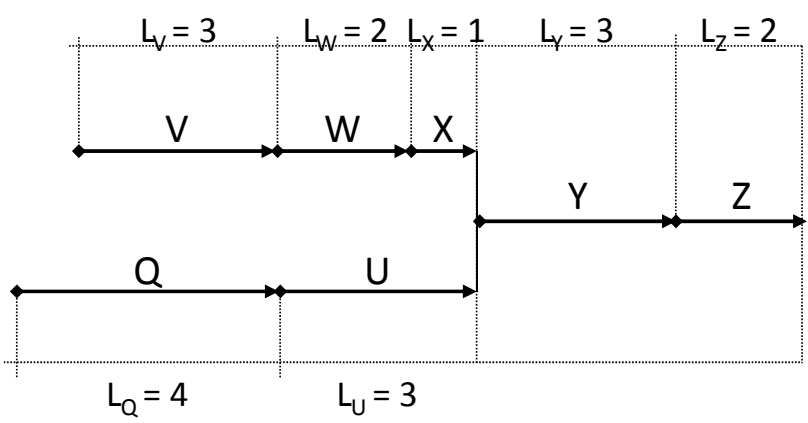

Fig. 2. The time-phased product structure for end product $\mathrm{Z}$

The total length of the longest branch (here $\mathrm{L}_{\mathrm{Z}}+\mathrm{LY}_{\mathrm{Y}}+$ $\mathrm{L}_{\mathrm{U}}+\mathrm{L}_{\mathrm{Q}}=2+3+3+4$ ) represents the total supply lead time for end product $\mathrm{Z}\left(\mathrm{S}_{\mathrm{Z}}=12\right)$ and also represents the cumulative lead time of the product and will then be referred to as S.

In subsequent analyses, also the supply lead time for each individual items in the BoM is of interest. The item supply lead time for item $\mathrm{W}$, for example, is $\mathrm{S}_{\mathrm{W}}=\mathrm{L}_{\mathrm{W}}+$ $\mathrm{L}_{X}+\mathrm{LY}_{Y}+\mathrm{L}_{Z}=2+1+3+2=8 . \mathrm{LW}_{\mathrm{W}}=8$ is thus the individual lead time for $\mathrm{W}$ and $\mathrm{S}_{\mathrm{W}}$ is the total supply lead time for $\mathrm{W}$. The supply lead time for each item is illustrated in Fig. 3 and for this example the cumulative lead time for the product $\mathrm{Z}$ is $\mathrm{S}=\max \left\{\mathrm{S}_{\mathrm{Z}}, \mathrm{S}_{\mathrm{Y}}, \mathrm{S}_{\mathrm{X}}, \mathrm{S}_{\mathrm{W}}, \mathrm{S}_{\mathrm{V}}\right.$, $\left.\mathrm{S}_{\mathrm{U}}, \mathrm{S}_{\mathrm{Q}}\right\}=\mathrm{S}_{\mathrm{Q}}=12$.

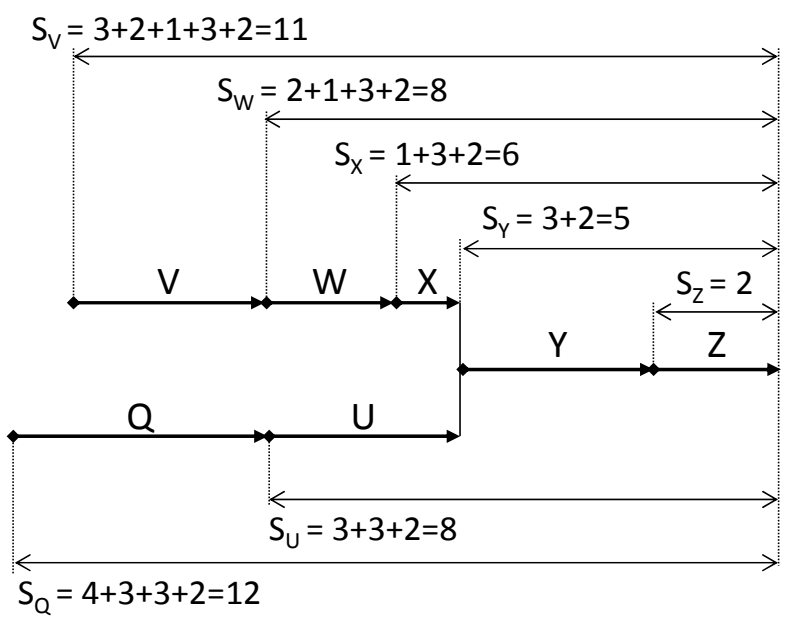

Fig. 3 . The time-phased product structure with item based supply lead times

The third step of the CDP method is focused on differentiating between forecast-driven items and customer-order-driven items. In order to do so, the customer order is related to the time phased product structure. This is done by identifying the delivery lead 
time (D). D indicates the time customers are willing to wait for delivery [8]. It is not based on a single customer whim but rather on general market requirements. The delivery lead time is associated with customer orders [9].

From a customer perspective, the delivery lead time is an important aspect of customer service. In some cases the delivery must be instant or the customer will try to find an alternative supplier. This is typical for many fastmoving consumer goods. In other cases the customer may accept to wait for delivery. The requested delivery lead time (sometimes also referred to as demand lead time) is of particular interest as it represents the requirements from the market.

The key role of D is highlighted when it is related to the supply lead time S. Previously this analysis has referred to $\mathrm{S}$ as $\mathrm{P}$ (production lead time) by e.g. [10] and [11]. Here we replace $P$ by $S$ to avoid the implicit connection to production since all types of supply are represented in this context. The S:D-ratio is the relation between the actual supply lead time (S) and the delivery lead time (D). The S:D-relation is associated with the level of certainty regarding a customer order. If the S:Drelation (that is the supply lead time divided by the delivery lead time) is larger than 1 , some sourcing and possibly manufacturing activities have to be initiated before the provider has any information about the specific customer order (this is sometimes referred to as supply under uncertainty driven by speculation or forecast). This extension of $\mathrm{D}$ upstream coincides with the customer order decoupling point (CODP) [12] and hence the S:D ratio can be used for positioning the CODP. In addition the item based $\mathrm{S}$ enables a classification of each and every item as forecast-driven or customer-order-driven by comparing $\mathrm{S}_{\mathrm{i}}$ with $\mathrm{D}$.

Even though D implies that there is a customer order present and activities within $\mathrm{D}$ can be customized for $\mathrm{a}$ specific customer order, this is not a requirement.

The fourth step in the CDP-method differentiates generic items from unique items corresponding to a customization analysis where the adapt lead time (A) is introduced [5]. Unique items can be either customer unique or customer-order-unique according to [5].

Lead time $A$ can be determined either from a demand perspective $\left(A_{D}\right)$ or a supply perspective $\left(A_{S}\right)$. From a demand perspective, $A_{D}$ would indicate the amount of time that the customer is willing to wait for adapted products where $\mathrm{D}$ sets the limit for how long the customer is willing to wait. $A_{D}$ has been defined as: "Customerorder based, covering the customer-order-unique lead time” by [9]. For example, assume that the delivery lead time in the previous section was identified as $D=7$, see Fig. 4. Item $\mathrm{X}, \mathrm{Y}$, and $\mathrm{Z}$ can hence be adapted to customer-order requirements since they are within $\mathrm{D}$. Item $\mathrm{V}$ and $\mathrm{Q}$ on the other must have been supplied to forecast and Item $\mathrm{W}$ and $\mathrm{U}$ have already been released for manufacturing when the customer order is received. A from demand perspective is hence $A_{D}=6\left(L_{X}+L_{Y}+L_{Z}=\right.$ $1+3+2=6$ ) which means that items $\mathrm{X}, \mathrm{Y}$ and $\mathrm{Z}$ involves some kind of customization based on the customer requirements. As shown in Fig. 4 Item $U$ also provides opportunities for customization but since $U$ must already have been initiated it is less advantageous to customize.



Fig. 4. Alternative adapt lead times in relation to delivery lead time

A can also be determined from a supply perspective. $A_{S}$ is then defined as the part of the BoM that can be customized. Assume that item $U$ in Fig. 4 can be customized. $A_{S}$ must then be 8 time units $\left(\mathrm{L}_{\mathrm{U}}+\mathrm{L}_{\mathrm{Y}}+\mathrm{L}_{\mathrm{Z}}=\right.$ $2+3+3=8$ ) in order for the customer to be able to affect the customization of $\mathrm{U}$. By requiring the customers to place orders with $\mathrm{D}=8$, also item $\mathrm{W}$ has the option to be customized.

Using a similar approach as for the S:D ratio a ratio can also be defined for this case. The A:D-ratio is the relation between adapt lead time (A) and the delivery lead time (D) is based on the demand side. The purpose of identifying the A:D-relation is to identify the portion of $D$ that is customer-order-unique. The A:D-relation hence highlights that even if a flow is customer-order-driven, it is not necessarily customized for that particular customer order. This ratio can be used to position the customer adaptation decoupling point (CADP) in a similar way as was done for the CODP [5].

The fifth step, finally, is where purchasing is targeted. From a more general perspective purchasing is related to activities taking place beyond the control of the focal company. These activities are categorized as external activities and in a corresponding way e.g. manufacturing and warehousing activities of the focal company are categorized as internal activities.

Internal lead time (I) is the time needed internally, for example for goods receiving, goods handling, quality checking, manufacturing, assembling, testing, and packaging. The transportation lead time from focal actor to customer can maybe also be included in the internal lead time, otherwise it is separately stated under its own heading. Internal lead time is hence similar, but not equal to, the manufacturing lead time [8]. Here we define the internal lead time as the cumulative lead time of all activities from the end item to the item in question as shown in Fig. 5. The internal lead time associated with end item $\mathrm{Z}$ is $\mathrm{I}_{\mathrm{W}}=\mathrm{L}_{\mathrm{W}}+\mathrm{L}_{\mathrm{X}}+\mathrm{L}_{\mathrm{Y}}+\mathrm{L}_{\mathrm{Z}}=8$ and $\mathrm{I}_{\mathrm{U}}=\mathrm{L}_{\mathrm{U}}+$ $\mathrm{L}_{\mathrm{Y}}+\mathrm{L}_{\mathrm{Z}}=8$.

External lead time (E) is basically the time it takes to obtain a purchased item from the supplier. Depending on the supplier's inventory policy this time might include the supplier's external lead time, its internal lead time, and 
the transportation lead time needed to deliver to the focal actor. External lead time is associated with purchase order [9]. From a focal actor point of view, this part of the supply lead time is less controllable. The external lead times associated with end product $\mathrm{Z}$ in Fig. 5 are the two 'leaves' in the time-phased product structure, the purchased items $\mathrm{V}$ and $\mathrm{Q}: \mathrm{E}_{\mathrm{V}}=3$ and $\mathrm{E}_{\mathrm{Q}}=4$.

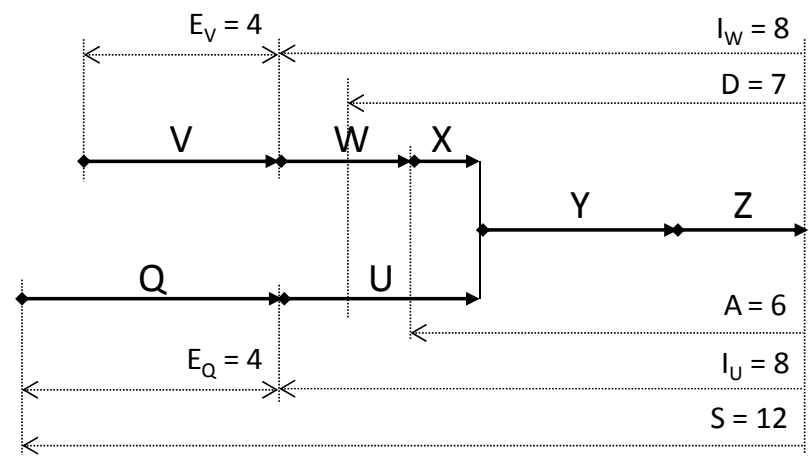

Fig. 5. Different lead times in relation to the time-phased product structure

This categorization of items as internal or external corresponds to the classification in terms of make or buy items. This approach does however provide additional information related to lead times since the items are not only classified as external but they are also positioned according to the time phased product structure. The previous steps of the CDP-method provided additional information about the market demand in terms of e.g. D and $\mathrm{A}$. By comparing the different $\mathrm{S}_{\mathrm{i}}$ for external items to $\mathrm{D}$ and $\mathrm{A}$ the purchased items can be classified in terms of driver and uniqueness. Table 1 provides a simplified perspective of the classification where four different categories are identified. A more extensive analysis is provided in [5].

TABLE I

CATEGORIZATION OF PURCHASED ITEMS

\begin{tabular}{|l|c|c|}
\hline & $\begin{array}{c}\text { Forecast-driven } \\
\text { (FD) }\end{array}$ & $\begin{array}{c}\text { Customer-order- } \\
\text { driven (COD) }\end{array}$ \\
\hline Standardized $(\mathrm{St})$ & FD-St & COD-St \\
\hline Customized $(\mathrm{Cu})$ & FD-Cu & COD-Cu \\
\hline
\end{tabular}

Table 1 summarizes the key results from the first phase of the CDP-method. Each purchased item is categorized in terms of key aspects related to customerdriven manufacturing [13]. First of all the items are differentiated in terms of drivers related to the CODP. Forecast-driven purchased items are items purchased based on expectations about future sales and will be inventoried. For this type of items the service level of the inventory is usually an important performance measure. For items purchased based on a particular customer order, important measures are different and usually related to delivery speed and delivery reliability. These two types of requirements are supported by different types of supplier relations and are hence important to consider from a purchasing perspective. The uniqueness provides additional challenges and in total three main scenarios are identified since customized products should not be forecast-driven.

\section{DISCUSSION AND CONCLUSION}

A strategy for purchasing has traditionally emphasized price as a key component. A lower price has been considered as a better deal as long as the good or service fulfills the provided specification. More integration along the supply chain has however increased the emphasis on other aspects of supplier relations. The combination of focus on core competence, generating outsourcing initiatives, and higher level of customization creates more complex supply networks. It is not enough in this context to only focus on low price. Instead each actor must provide supply in line with the competitive priorities in focus for each individual actor. Purchasing may then differentiate between cases where speculation is necessary and cases where the end-customer's customer order may be used as a trigger for activities. By also including issues related to customization the supplier relation may be further differentiated.

In summary the tool suggested here provides input to purchasing in terms of how purchasing can support the company's competitive priorities in a more elaborate way. In particular the time-phased approach outlined here introduced two new perspectives.

- First an extended analysis of S:D relation for categorizing all items in a BoM in terms of the driver of the item based on item based $\mathrm{S}$ :D relation $\left(\mathrm{S}_{\mathrm{i}}\right)$.

- Second, a more elaborate perspective of customization was introduced in terms of the possible level of customization $\left(A_{S}\right)$ and the requested level of customization $\left(A_{D}\right)$.

The tool outlined here is based on deterministic leadtimes which is in line with e.g. materials planning using MRPII and its derivatives. In this case uncertainties are handled by buffers using queue times integrated into the lead time estimates and safety stocks at item level. This deterministic approach is also in line with aggregate planning where the coefficient of variation is reduced by considering the properties of product families instead of focusing on individual products. An interesting extension to research further would however be to investigate how stochastic properties could be integrated into the suggested tool.

\section{ACKNOWLEDGMENT}

The application of the time-phased product structure analysis concept has been investigated in six companies based on the research project KOPeration covering the alignment of key aspects of purchasing strategy with operations strategy. This research is partly funded by the Swedish Knowledge foundation (KKS), and partly by the participating companies. 


\section{REFERENCES}

[1] P. Kraljic, "Purchasing Must Become Supply Management," Harvard Business Review, vol. 61, pp. 109-117, 1983.

[2] J. Wikner and J. Bäckstrand, "Aligning operations strategy and purchasing strategy," in $18^{\text {th }}$ International Annual EurOMA Conference, Cambridge, UK, 2011.

[3] J. Bäckstrand, E. Johansson, J. Wikner, R. Andersson, B. Carlsson, A. Hjertén, et al., "A method for customer-driven purchasing," in 20th International Annual EurOMA Conference, Dublin, Ireland, 2013.

[4] J. G. Wacker, "A definition of theory: research guidelines for different theory-building research methods in operations management," Journal of Operations Management, vol. 16, pp. 361-385, 1998.

[5] J. Wikner and J. Bäckstrand, "Decoupling points and product uniqueness impact on supplier relations," in $19^{\text {th }}$ International Annual EurOMA Conference, Amsterdam, The Netherlands, 2012.

[6] J. Wikner and M. Rudberg, "Introducing a customer order decoupling zone in logistics decision-making," International Journal of Logistics: Research and Applications, vol. 8, pp. 211-224, 2005.

[7] J. T. Clark, "Capacity management," in 1979 APICS Conference, p. 190.

[8] APICS. APICS Dictionary (13 ${ }^{\text {th }}$ ed., 2011 ed.). Available at http://www.apics.org/industry-content-

research/publications/apics-dictionary, accessed 5 July 2012

[9] J. Wikner, "Lead time based framework for cusromer-order based management [Ledtidsbaserat ramverk för kundorderstyrning]" in 13th Research and Application Conference on Logistics and Operations Management [PLANs forsknings- och tillämpningskonferens], Norrköping, Sweden, 2011.

[10] S. Shingo, A Study of the Toyota Production System - From an Industrial Engineering Viewpoint, Revised and Retranslated ed. Cambridge, MA: Productivity press, 1981.

[11] H. Mather, "Attack your P:D Ratio," in 1984 APICS Conference.

[12] S. Hoekstra and J. Romme, Eds., Integrated Logistics Structures: Developing Customer Oriented Goods Flow. New York, NY: Industrial Press, 1992.

[13] J. C. Wortmann, D. R. Muntslag, and P. J. M. Timmermans, Eds., Customer-driven manufacturing. London, UK: Chapman \& Hall, 1997. 